\title{
PIV による昆虫羽ばたき翼の空カメカニズムの可視化*
}

\author{
永井 弘人 $* *$, 磯貝 紘二**, 藤本 達見 $* *$
Flow Visualization of Aerodynamic Mechanism of Insect Flapping Wings using PIV

\author{
Hiroto Nagai, Koji Isogai and Tatsumi Fujimoto
}

\section{1. 緒 言}

超小型飛翔機（Micro Air Vehicle：MAV）の開発が 注目されているが，その飛行形態として昆虫の羽ばたき 飛行は有望な候補であると考えられている。日本文理大 学マイクロ流体技術研究所では, トンボの羽ばたき飛行 を模擬した超小型飛翔ロボット1)の研究開発を行ってい る（Fig. 1)。羽ばたき型超小型飛翔ロボットの開発で は, 機体の軽量化と羽ばたき翼の推力増加が課題となる が，一般的に両者は相反する。そのため，高効率の羽ば たき翼の開発が望まれるが, 羽ばたき翼の空力性能は非 常に多くの設計パラメー夕に支配されており, 羽ばたき 翼の設計手法はまだ確立されていない.

近年の多くの研究によって, 昆虫の羽ばたき飛行に起 きている様々な空力現象一Delayed stall, Rotational circulation, Wake capture一が明らかになってきた ${ }^{2-5)}$. 実際の昆虫の羽ばたき飛行は非常に複雑で, それを完全 にMAVで実現することは容易ではない.MAVの開発 では，機械的に実現可能なシンプルな羽ばたき翼が望ま れる。本研究は, 羽ばたき翼の設計パラメー夕が空力特 性に与える影響を調べることで, MAV 開発のための指 針を示すことを目的としている。ここでは，昆虫の翅を 模擬した平板剛体翼のスケールモデルを水中で羽ばたか せ，それに働く非定常空気力の測定および翼まわりの流 れの可視化を行った。実験結果から，羽ばたき翼を支配 する設計パラメー夕 (無次元振動数, 平面形状, 羽ばた き運動パターン）と空力性能の関係，およびその非定常 空力メカニズムを明らかにした ${ }^{6-10)}$. 羽ばたき翼のス ケールモデルを使った実験は非常に有効な手段としてこ れまで多く用いられてきた ${ }^{3-5)}$ が，それらは静止流体中 で行われたホバリング飛行を模擬した実験であった。本 研究では, 回流式水槽を用いて一様水流中での羽ばたき 翼のスケールモデル実験を行い, 前進飛行時における羽 ばたき翼の非定常空力現象も明らかにした。本稿では,

* 原稿受付 2010 年 7 月 15 日

** 非会員 日本文理大学 マイクロ流体技術研究所 (干 870-0397 大分市一木 1727, E-mail : nagai@nbu.ac.jp)

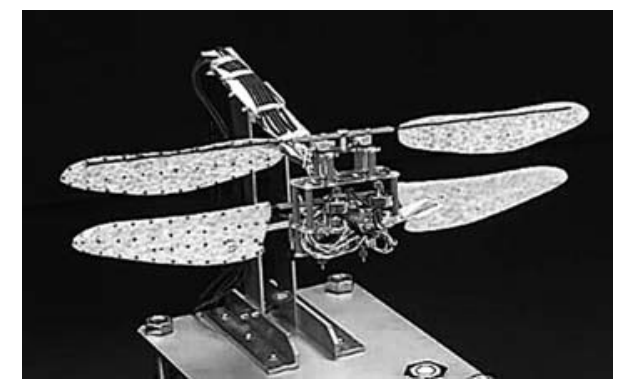

Fig. 1 A dragonfly-type micro air vehicle.

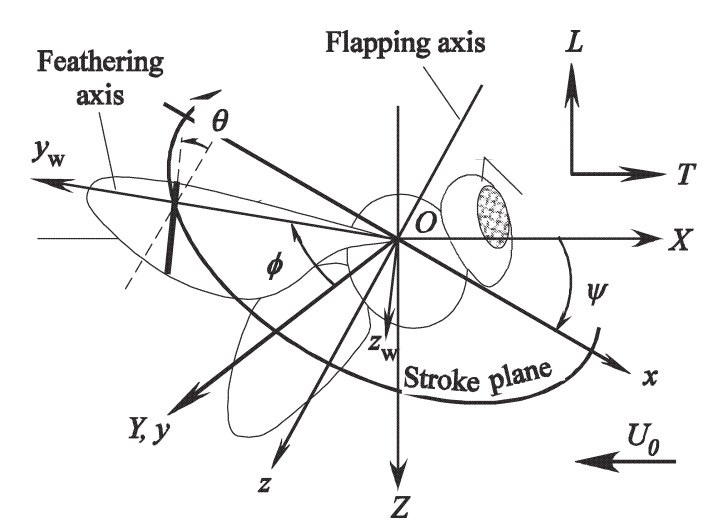

Fig. 23 d-coordinate system of a flapping wing.

これらの研究成果について, PIVを用いた流れの可視 化による結果を中心に紹介する。

\section{2. 実験方法}

\section{1 羽ばたき運動}

羽ばたき運動の座標系を Fig. 2 に示す. 羽ばたき運 動は体軸（z軸）周りの回転運動であるフラッピング運 動と, 翼のスパン軸 $\left(y_{w}\right.$ 軸) 周りの回転運動である フェザリング運動から成る。これら 2 つ運動の組み合 わせで昆虫は様々な飛行を実現している。翼のストロー ク面（x-y 面）は水平面に対してストローク角 $\psi$ だけ 傾いており，ホバリング飛行の場合は $\phi=0$ となる.

実際の昆虫の羽ばたき運動は非常に複雑な動きをして いる11)が，その運動を単純な台形波でモデル化する。台 形波型羽ばたき運動におけるフラッピング角 $\phi$ とフェ ザリング角 $\theta$ の角度と角速度の時間履歴を Fig. $3 \mathrm{a}, \mathrm{b}$ 


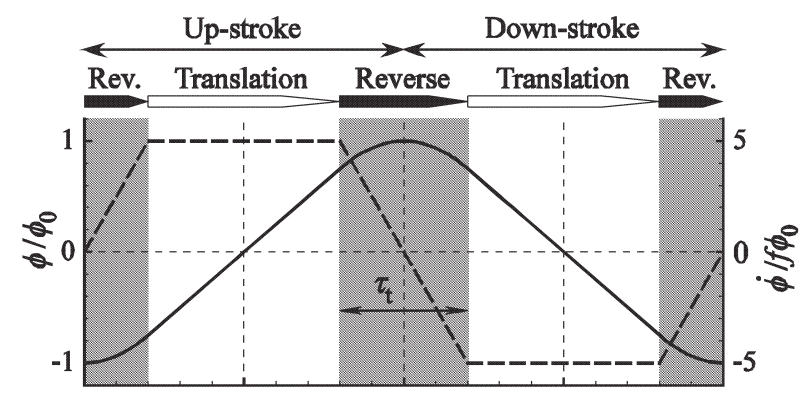

a) Flapping motion

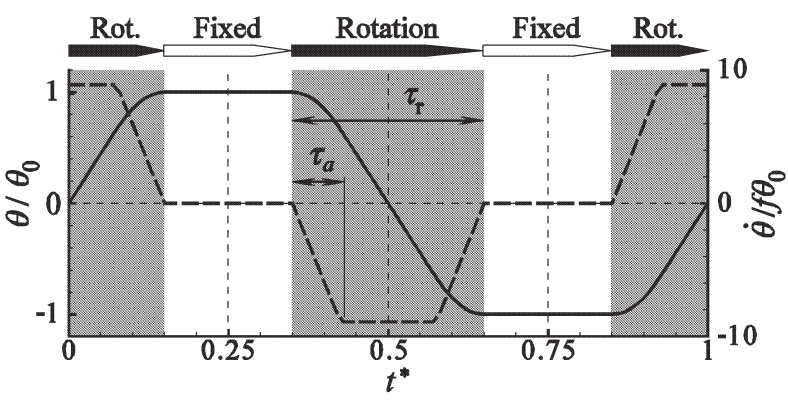

b) Feathering motion

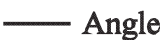

---- Angular velocity

Fig. 3 Time histories of wing kinematics.

にそれぞれ示す。ここで横軸は羽ばたき周期を 1 とする 無次元時間である。台形波型フラッピング運動は，一定 フラッピング角速度で移動する並進フェーズ（Translational phase) と，加減速運動を伴ってストローク方 向を変える切返しフェーズ（Reversal phase）に分けら れる。台形波型フェザリング運動は，一定の迎角に固定 される固定角フェーズ (Fixed-angle phase) と，回転 運動を行う回転フェーズ（Rotational phase）に分けら れる。ここで， $\tau_{t}$ は切返しフェーズ時間， $\tau_{r}$ は回転 フェーズ時間， $\tau_{a}$ はフェザリング回転運動の加減速時 間であり，それぞれ羽ばたき周期で無次元化して表す。

\section{2 実験装置}

本研究では羽ばたき翼のスケールモデルを水中で羽ば たかせ，羽ばたき翼に働く流体力の計測と翼まわりの流 れの可視化を行った。羽ばたき翼のスケールモデル装置 を Fig. 4 に示す. 翼モデルはスパン $100 \mathrm{~mm}$, 厚さ 1 $\mathrm{mm}$ の平板翼で, マルハナバチの平面形状を模擬して いる。この翼は実験において変形が微小になるように設 計されており，剛体翼と仮定できる。フラッピング運動 とフェザリング運動は，2つのモー夕を用いてそれぞれ 独立に実現される，流体による荷重およびトルクは翼根 に取り付けられたひずみゲージを用いて測定され，翼面 に垂直成分の流体力とフラッピング軸周りのトルクを測 定する。このスケールモデル装置は水槽の上に設置され, 翼は水中で羽ばたく。本研究では日本文理大学マイクロ 流体技術研究所の回流式水槽を用いて，ホバリングから 高速前進飛行までを模擬した実験を行った。

実験結果が昆虫の羽ばたき飛行時の流れと相似である ためには, レイノルズ数 $R e$, 無次元振動数 $k$, 前進比

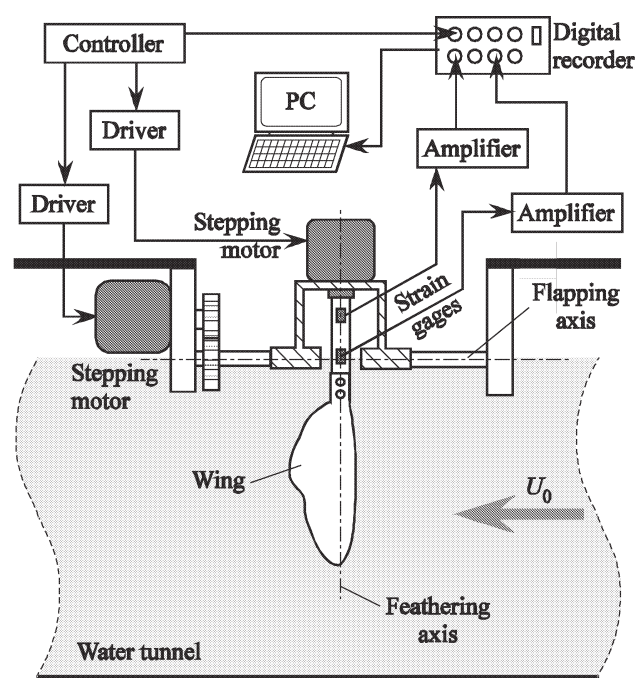

Fig. 4 Dynamically scaled model for force measurement.

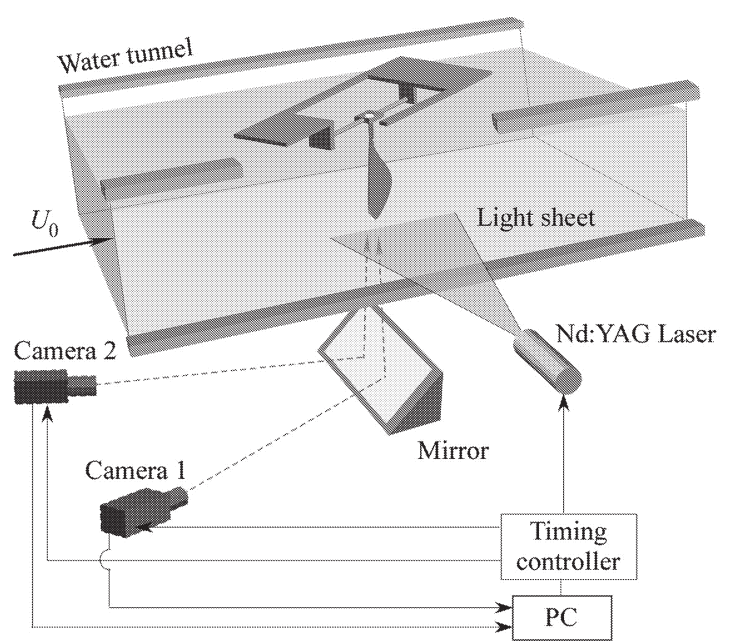

Fig. 5 Digital particle image velocimetry system.

$J$ の 3 つの無次元パラメータを一致させなければならな い. 本研究では代表長さを $2 / 3$ セミスパン位置でのセミ コード長 $b$, 代表速度をその位置での最大フラッピング 速度として，Re=2000-5000，k=0.167，J=0-0.5 程度の範囲で実験を行った。

流れの可視化のために用いた粒子画像速度測定法 (PIV) システムを Fig. 5 に示す. Nd：YAGレーザは 水槽側面を通して翼断面に垂直に照射され，2台のカメ ラによって水槽下面から撮影する。翼はレーザが通過で きるように透明なアクリル板を用いた。レーザ面は，翼 のスパン方向に対して異なる 11 断面について撮影し, 最後にデータを統合して翼全体の流れ場を表現する。 ターゲット粒子としてナイロン粒子（ $\rho=1.02 \mathrm{~g} / \mathrm{cm}^{3}$, $d=4.1 \mu \mathrm{m})$ を用い, 速度解析用のソフトウェアとし て LaVision 社製 Davis 7.1 を用いた8).

\section{3. 羽ばたき翼の空カメカニズムの可視化}

本節では羽ばたき翼の空力特性を支配する主な 3 つの 空力メカニズムーDelayed stall (遅延失速), 
Rotational Circulation (回転循環), Wake capture (後流捕獲)一について，それぞれが流体力に与える効 果を流れのメカニズムと関連付けて考察する。

\subsection{Delayed stall（遅延失速）効果}

Delayed stall 効果は, 翼前縁に付着した前縁渦 (LEV) による負圧によって，大迎角においても失速す ることなく非常に大きな揚力を生み出すことである.

Fig. 6 は一定迎角 $(45 \mathrm{deg})$, 一定フラッピング速度で 動いているときの翼まわりの渦度の様子を PIVにより 可視化したものである. Fig. 6 から分かるように，45 deg の大迎角であっても，一定速度で動くフラッピング 運動では，決して前縁渦は翼から離れることなく安定に 付着している，翼のフラッピング運動によって前縁渦の 中心にはスパン方向流れが発生し，これにより Delayed stall は安定で定常的な現象となり，その効果は瞬間の フラッピング速度と迎角によって決定される。ここで Delayed stall 効果を測定するために，翼を一定の迎角 に固定したまま，一定のフラッピング速度で動かしたと きの揚力を測定し，迎角との関係を調べた。その結果を Fig. 7 に示す．比較のために翼を一定迎角，一定速度で 平行移動した場合，すなわち固定翼として用いた場合の 揚力係数も同時に示す. Fig. 7 より，Delayed stall 効 果は，大迎角においては固定翼として用いた場合よりも 大きな揚力係数が得られることが分かる.

この結果に基づいて，羽ばたき運動中の Delayed stall 効果を，瞬間のフラッピング速度と迎角を用いて 準定常的に見積もった.Fig. 8 は実際の羽ばたき運動に よる揚力係数と Delayed stall の寄与とを比較した片ス

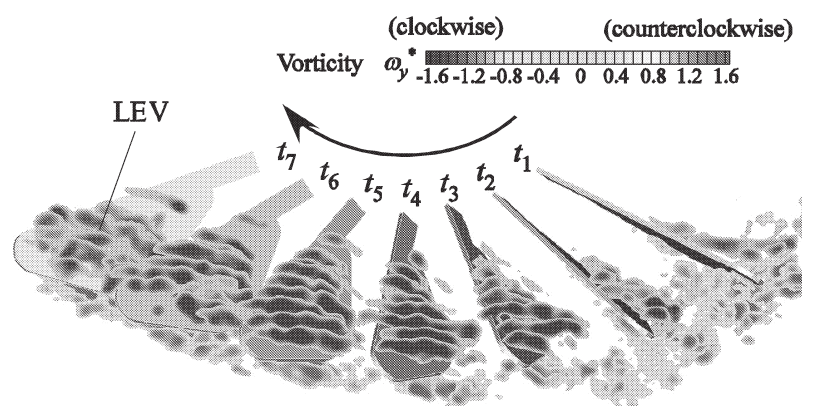

Fig. 6 Vorticity sequence around the flapping wing during a translational phase with a fixed-angle.

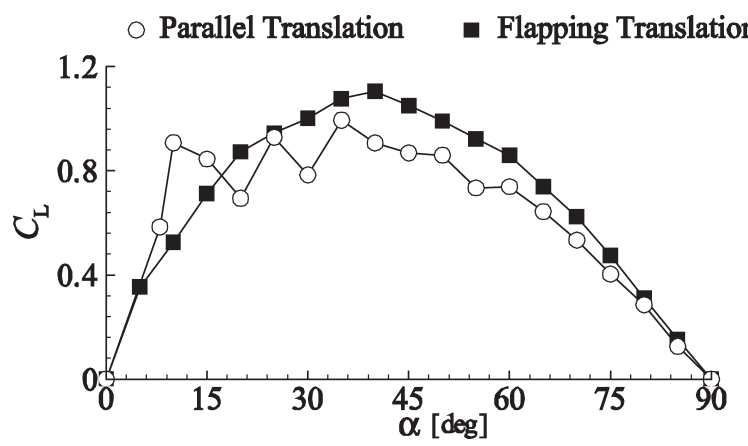

Fig. 7 Lift coefficient of delayed stall vs. angle of attack.

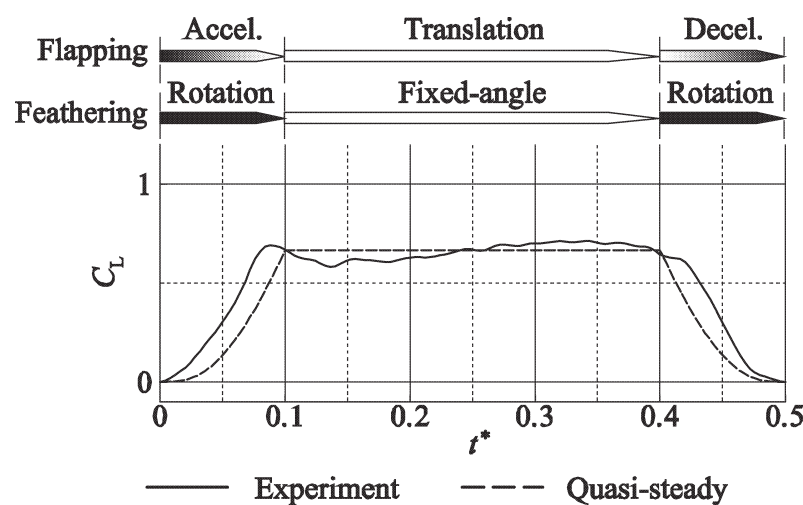

Fig. 8 Time history of contribution of delayed stall effect.

トローク時間履歴である。一定迎角，一定フラッピング 速度で移動している並進一固定角フェーズ区間では，両 者は非常に良く一致している。それ以外の区間では，大 きな不一致が見られるが，これは加減速運動やフェザリ ング運動による非定常効果である。 Delayed stall 効果 は時間平均揚力の約 $90 \%$ を占め，昆虫が大きな揚力を 得る上で最も重要な効果である。

\subsection{Rotational circulation（回転循環）効果}

Rotational circulation 効果は, 翼のフェザリング回 転運動によって生じる. Fig. 9 は，フラッピング並進 フェーズ中にフェザリング回転運動を行った場合の流体 力係数（翼面に垂直方向流体力）の片ストローク時間波 形と，それに対応する翼まわりの渦度の様子である。

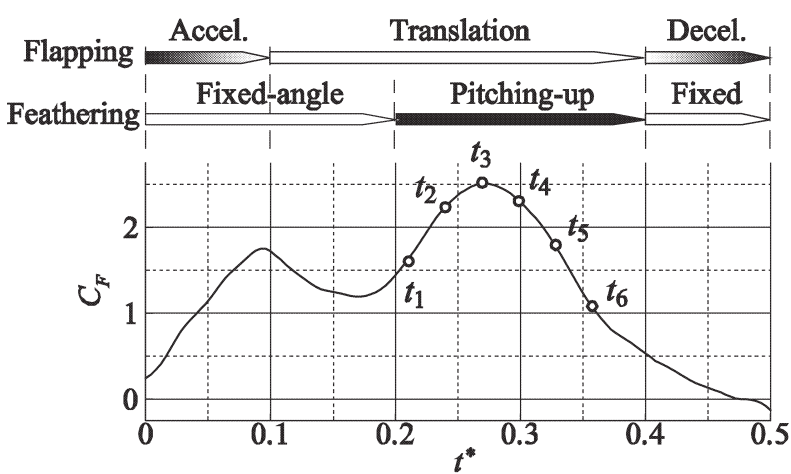

a) Time history of normal fluid force coefficient.

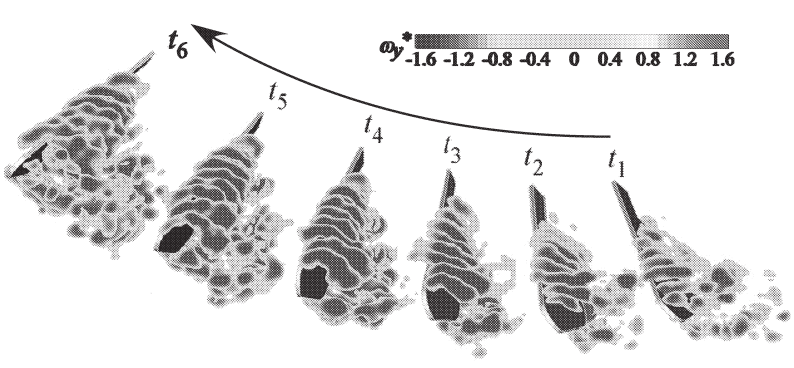

b) Vorticity sequence during rotational phase.

Fig. 9 Time history of fluid force coefficient and the corresponding vorticity sequence around the wing during a rotational phase with a translational phase. 
Fig. 9 から分かるように回転フェーズが始まると流体力 は急激に増加する。このとき，翼に付着していた前縁渦 は回転によって急激に成長している。また，回転による 前縁渦の成長に伴って，翼後縁からも回転方向が逆向き の渦が発生し, 両者で渦対を形成する（回転渦対： $\mathrm{RV})$. 回転による流体力の増加は揚力の増加に寄与す るが，それに伴うパワーの増加量の方が大きく効率は低 下する。なぜなら，回転によって増加した流体力べクト ルは，翼のピッチアップによって上向きよりもむしろ水 平方向を向くため, 揚力よりも抵抗として働き, 結果と して必要パワーの増加を招くからである。フェザリング 回転運動の夕イミングは，揚力やその効率に大きな影響 を与え，回転運動はフラッピング運動の並進フェーズで 行うよりも，切返しフェーズで行う方が効率の観点から 効果的であることが分かった7).

\subsection{Wake capture (後流捕獲) 効果}

Wake capture は，前のストロークに翼自身が作った 流れの中を，切返しによってもう一度翼が通過すること により起きる現象である。 Wake capture効果は前のス トロークでの翼の動きに密接に関係する。本研究から, 無次元振動数と回転のタイミングが Wake capture 効 果に大きな影響を与えることが分かった ${ }^{9}$. Fig. 10 は， 回転の夕イミングを早めた場合 (Advanced motion) の揚力係数の 1 サイクル時間波形である. Wake capture 効果と翼まわりの流れの関係を調べるために，Fig. 11 にPIVにより計測した $50 \%$ スパン位置での翼周りの 流れを示す。ここでFig. 10 の $t_{1}$ - $t_{6}$ は Fig. 11 のそれら と対応している. Fig. 10 で注目すべきは, フラッピン グ速度が 0 となる切返し地点 $\left(t^{*}=0.5\right)$ において, 揚 力が発生している点である。これはまさにWake capture 効果を示している。これを流れ場から考察する.

Fig. 11 $\left(t_{3}\right)$ より, 回転運動によって翼の前縁と後縁か らお互いに逆向き回転の渦対 $(\mathrm{RV})$ が発生している. そして，この回転が逆向きの渦対の間には強い流れが誘 起されている. Fig. 11 $\left(t_{4}\right)$ はちょうど切返しに対応し ており翼は静止しているが，渦対によって誘起された流 れを翼が受けることで，大きな揚力が発生している。前 のストトークで誘起された流れの中で，次のストローク

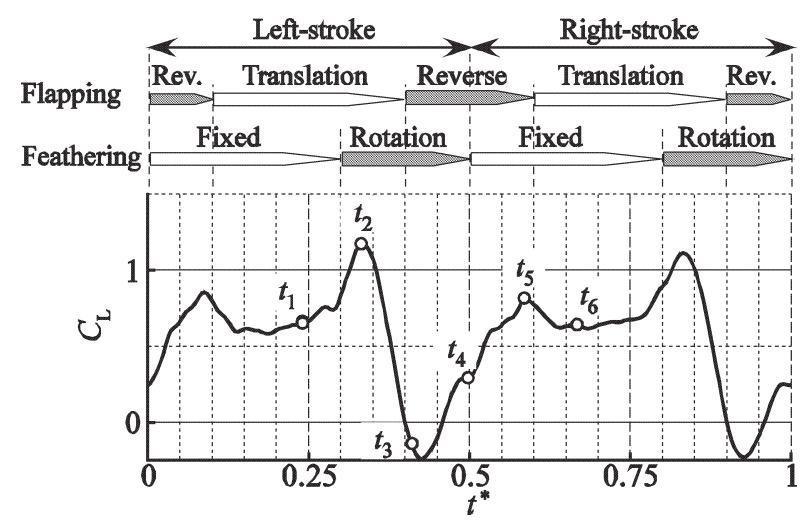

Fig. 10 Time history of CL in advanced motion.
が始まるため，ストローク初期 $\left(t^{*}=0.5-0.6\right)$ では大 きな揚力が得られるが, 後縁から出発渦の放出 (Fig. $\left.11\left(t_{5}\right)\right)$ と共に揚力は一度減少し (Fig. $\left.10\left(t_{5}\right)\right)$, その後 新しい前縁渦を形成する（Fig. 11( $\left.\left.t_{6}\right)\right)$.

\section{4. 前進飛行時の空カメカニズムの可視化}

前節では，ホバリング時における羽ばたき翼の空力メ カニズムついて紹介した。前進飛行時には，ホバリング 時と異なって揚力と同時に推力を発生させる必要がある ために，羽ばたきのストローク面を傾ける必要がある. そのため, 打ち上げと打ち下ろしとでは, 翼への流入速 度や有効迎角が異なる。ここでは，ホバリング時と異な る空力メカニズムの一例を示す。ホバリング飛行の場合, Wake capture 効果はどちらの切返し部分でも同じよう に働いたが，前進飛行時には，打ち上げから打ち下ろし

LEV: Leading-edge vortex RV: Rotational vortices SV: Starting vortex
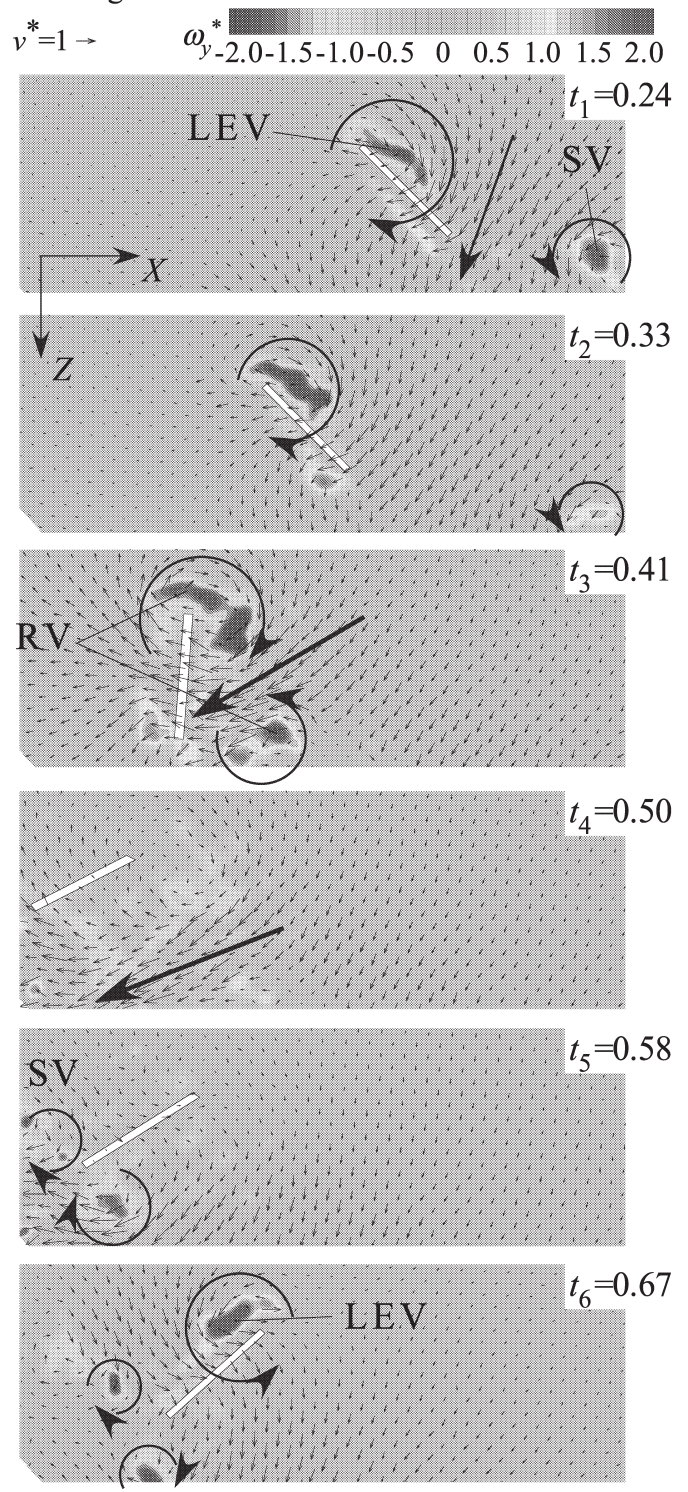

Fig. 11 Flow pattern sequence around the airfoil at 50\% semi-span location in advanced motion. 
の切返しと，打ち下ろしから打ち上げの切返しで効果が 異なる。この理由を流れの可視化の結果を使って説明す る. Fig. 10，11 と同じ羽ばたき運動で，ストローク角 $\psi=45 \mathrm{deg}$, 八チにとって中速の前進比 $J=0.2$ の場合 の，羽ばたき翼まわり渦度の様子を Fig. 12 に示す。

Fig. 12 a は打ち上げから打ち下ろしにかけての様子で あるが，打ち上げに作られた渦は，打ち下ろしが始まる と一様流によって後方に流され翼から遠ざかる。一方,

Fig. 12 b は打ち下ろしから打ち上げにかけてであるが, 打ち下ろし時に作られた渦は, 一様流と打ち上げの方向 が同じであるため，相対的に翼のまわりに留まっている。

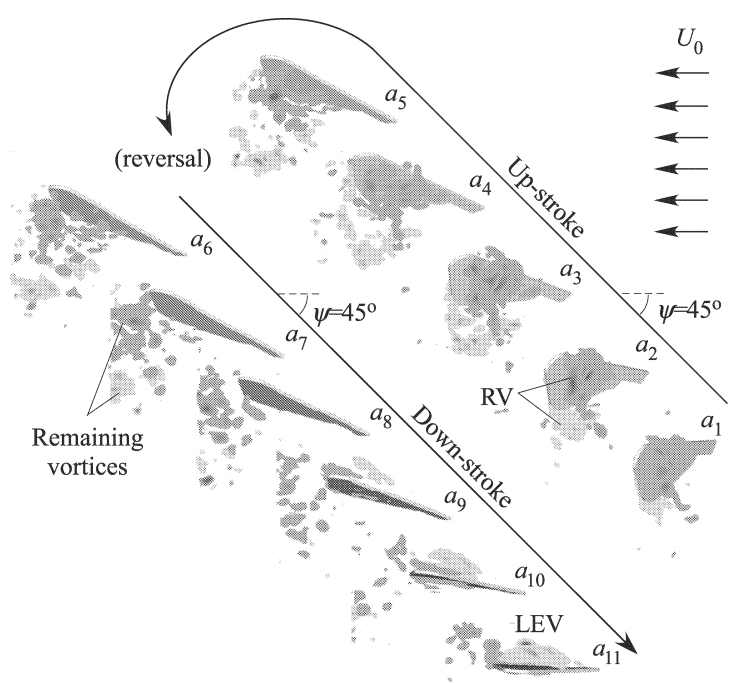

a) Up- to down-stroke.

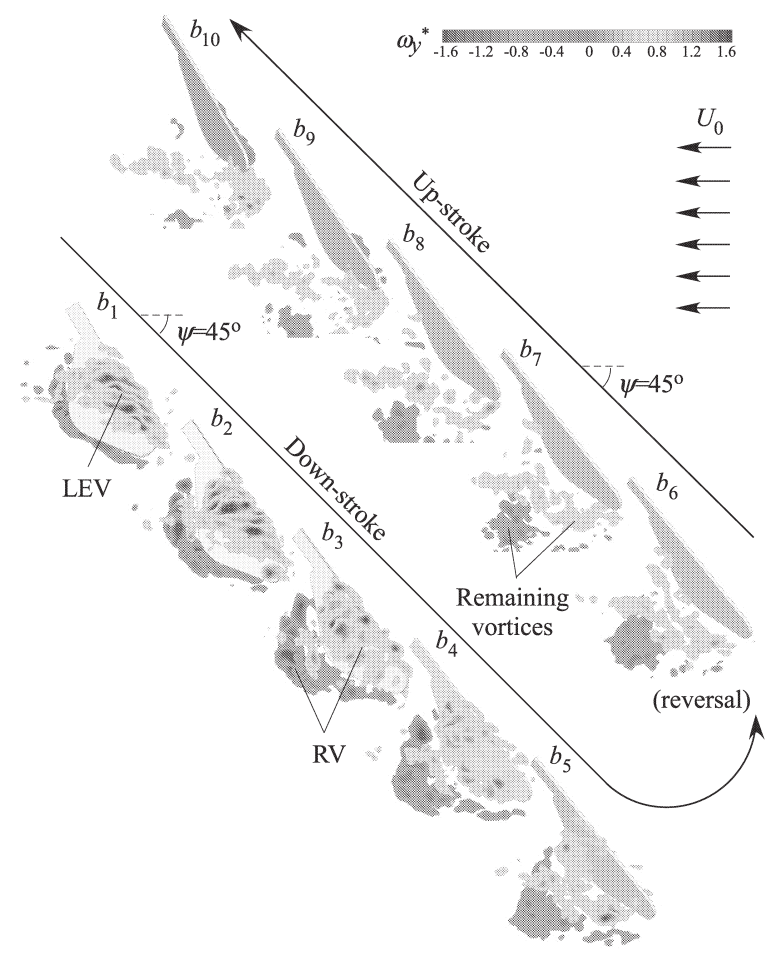

b) Down- to up-stroke.

Fig. 12 Vorticity sequences around the wing in forward flight of $J=0.2$ at $\psi=45 \mathrm{deg}$.
したがって，前進飛行時には打ち上げから打ち下ろしに 変わる切返しではWake capture効果が弱く, 逆に打 ち下ろしから打ち上げに変わる切返しでは Wake capture 効果が高い9.

\section{5. 前後 2 枚羽ばたき翼の空カメカニズムの可視化}

多くの昆虫は 4 枚の翅を持っているが, 前翅と後翅が ヒンジなどで接続されて，あたかも前後で 1 枚の羽ばた き翼のように翅を動かす。一方，トンボは 4 枚の前後左 右の翅を独立に動かすことができ, したがって, 前後翼 間には複雑な流れの干渉が存在する。前節に示したのは 八チの翅を模擬した 1 枚羽ばたき翼における空力メカニ ズムであったが，ここでは前後 2 枚の羽ばたき翼におけ る空力干渉効果について紹介する。前後 2 枚翼の羽ばた き運動の間にはある位相差らがあり，それが空力干渉 効果と密接な関わりを持つ. Fig. 13 は, 前後位相差 $\zeta$ と前後翼それぞれの揚力係数との関係を示す。ここで後 翼が先行して動く場合を $\zeta>0$ とし, 前翼が先行して動 く場合を $\zeta<0$ とする. 本実験では, 実際のトンボの観 測結果に基づき, 前翼のフラッピング振幅を $40 \mathrm{deg}$,

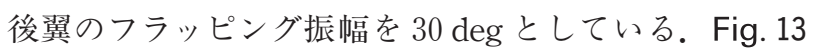
より 1 枚翼の揚力係数と比較すると, 前翼は前後位相差 に対してそれほど影響を受けないが, 後翼は $\zeta=45 \mathrm{deg}$ のとき 1 枚翼よりも大きな揚力が発生していることが分

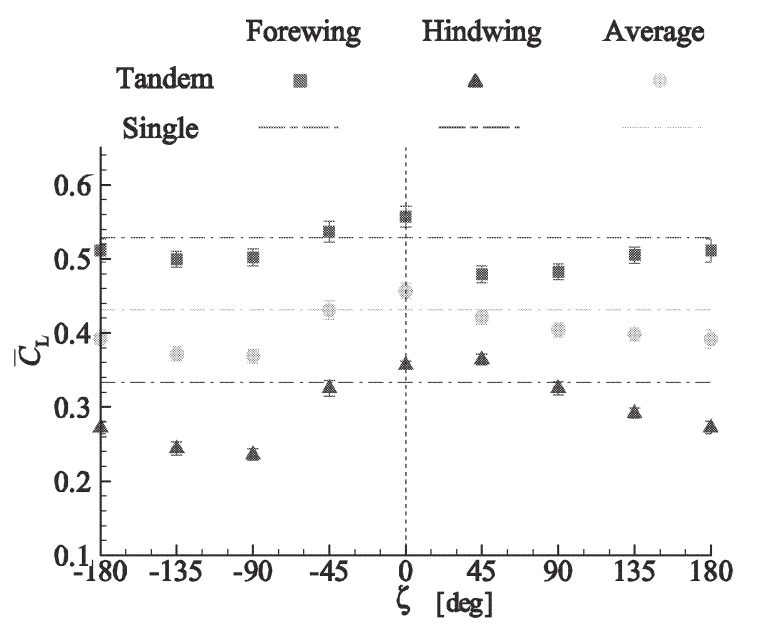

Fig. 13 Lift coefficients with respect to phase difference $\zeta$ between fore-and hindwings in hovering flight.

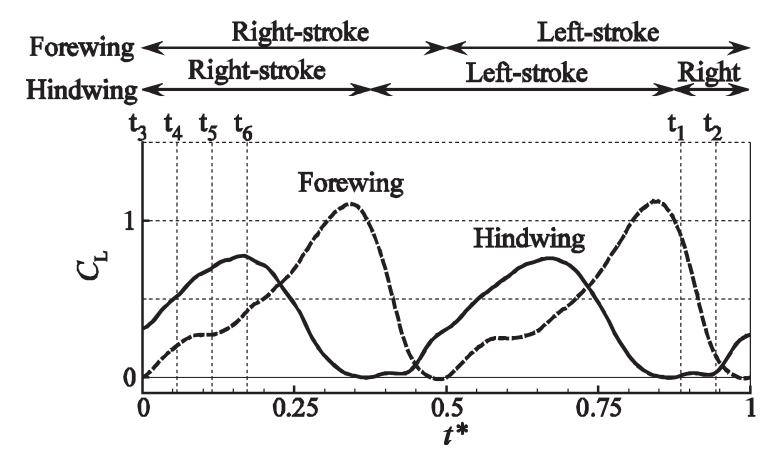

Fig. 14 Time histories of $C_{L}$ for fore-and hindwings. 
かる.

後翼の揚力が増強される $\zeta=45 \mathrm{deg}$ の場合の揚力係数 の時間履歴と，それに対応する $50 \%$ 翼断面まわりの流 れ場を Fig. 14 と Fig. 15 にそれぞれ示す. Fig. 15 より, 時刻 $t_{1}$ では，後翼付近に小さな残留前縁渦が残ってい るが，ちょうどその時に前翼の後流下に入るため，すぐ に下向きに流され，Wake capture 効果はあまり得られ ない. 時刻 $t_{2}$ では前翼の後流に出発渦が吹き飛ばされ, その結果 $C_{L}$ は減少する。しかし次の瞬間 $t_{3}$ では, 前翼 の残留渦が後翼の後方に強い吹き下ろしを誘起するため に, 後翼で強い前縁渦が形成され $C_{L}$ は増加し始める.
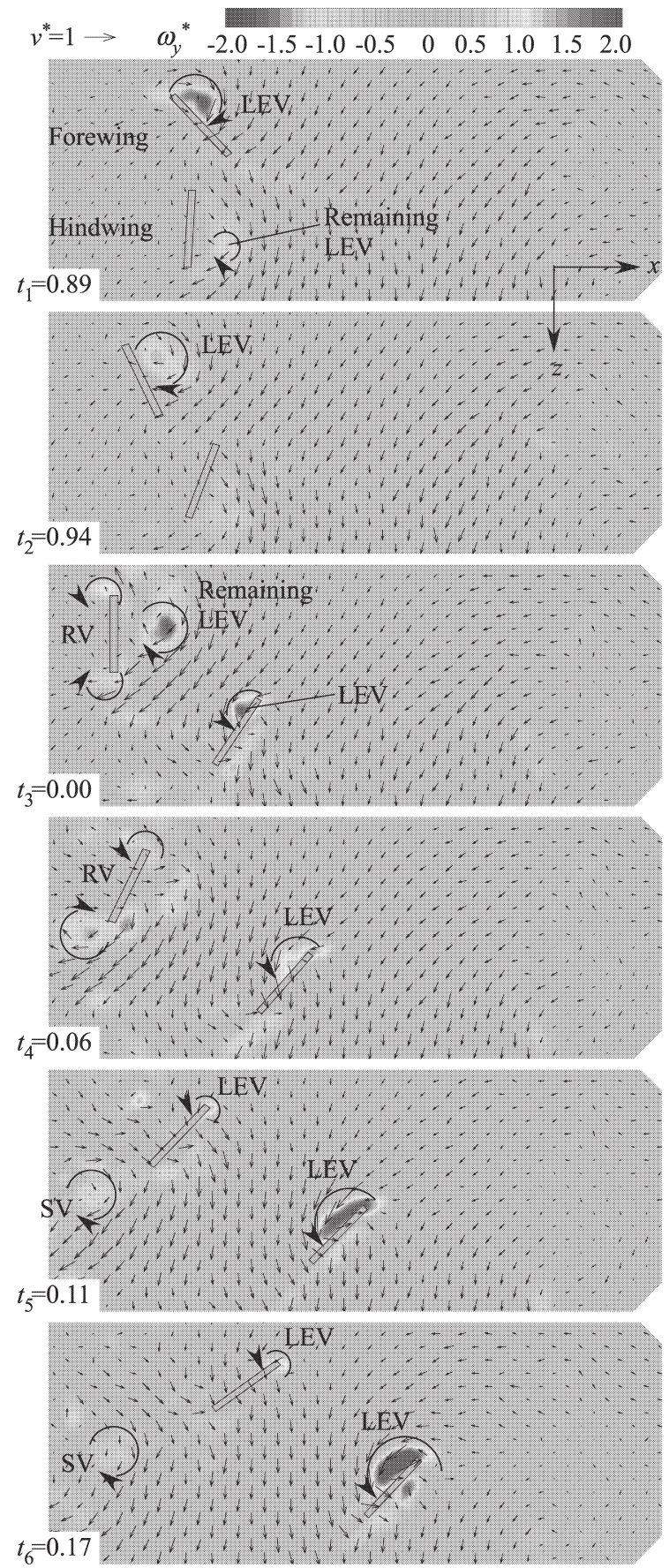

Fig. 15 Flow pattern sequence around the airfoils at 50\% semi-span location at $\zeta=45 \mathrm{deg}$.
その後 $t_{4} \sim t_{6}$ では, 前翼は常に後翼の左上に位置し，前 後翼の間に強い吹き下ろしが形成され，その結果後翼の 揚力は増加している10).

\section{6.おわりに}

本稿では，昆虫の羽ばたき翼を模擬したスケールモデ ルを水中で羽ばたかせ，その流体力の計測と PIVを 使った流れの可視化を行い，そこから明らかになった空 カメカニズムの一例を紹介した。本研究は剛体平板翼と して単純化したモデルにより，その設計パラメータの効 果について調べてきた。本研究により得られた羽ばたき 翼についての基礎的理解は，トンボ型超小型飛翔ロボッ トの開発においても非常に有用であった。多くの設計パ ラメータに支配された羽ばたき翼の設計開発には， CFD を使った数值シミュレーションの開発が重要であ るが，本実験結果は数值シミュレーションの検証用デー タとしても用いられている8).

\section{参考文献}

1) http://www.nbu.ac.jp/ $/ \mathrm{mfrl} /$

2 ) Ellington, C.P., Van den Berg, C., Willmott, A.P., Thomas, A.L.R. : Leading-edge Vortices in Insect Flight, Nature, Vol.384 (1996), pp.626-630.

3 ) Dickinson, M.H., Lehmann, F.-O., Sane, S.P. : Wing Rotation and the Aerodynamic Basis of Insect Flight, Science, Vol.284 (1999), pp.1954-1960.

4 ) Maybury, W.J., Lehmann, F.-O. : The Fluid Dynamic of Flight Control by Kinematic Phase Lag Variation between Two Robotic Insect Wings, J. of Exp. Biol., Vol.207 (2004), pp.4707-4726.

5 ) Yamamoto, M., Isogai, K. : Measurement of Unsteady Fluid Dynamic Forces for a Mechanical Dragonfly Model, AIAA J., Vol.43, No.12 (2005), pp.2475-2480.

6 ）永井弘人, 伊藤匠, 三浦慶太, 早瀬敏幸, 磯貝紘二 : ホバリ ング飛行における 3 次元羽ばたき翼の非定常空気力の測定 (第 1 報, レイノルズ数, 無次元振動数, 翼平面形状の影響), 日本機械学会誌論文集 (B 編)，73 卷，736 号 (2007), pp. $2450-2458$.

7 ) 2 Nagai, H., Isogai, K., Hayase, T. : Measurement of unsteady aerodynamic forces of $3 \mathrm{D}$ flapping wing in hovering to forward flight, Proc. of the 26 th ICAS (2008), CD-ROM.

8 ) Nagai, H., Isogai, K., Fujimoto, T., Hayase, T. : Experimental and Numerical study of forward flight aerodynamics of insect flapping wing, AIAA J., Vol.47, No.3 (2009), pp.730-742.

9 ) Nagai, H., Isogai, K., Fujimoto, T. : Experimental study of wing-wake interactions of insect flapping wing, Proc. KSAS-JSASS Joint International Symposium on Aerospace Engineering, Cheju, Korea, (2008), pp.133-140.

10) Nagai, H., Isogai, K., Fujimoto, T. : Experimental study on flow interaction between fore- and hindwings of dragonfly in hovering and forward flight, Proc. of the 27 th ICAS (2010), CD-ROM.

11) Dudley, R., Ellington, C.P. : Mechanics of Forward Flight in Bumblebees. I. Kinematics and Morphology, J. Exp. Biol., Vol.148 (1990), pp.19-52. 